Article

\title{
Study on the Fabrication of Porous TiAl Alloy via Non-Aqueous Gel Casting of a $\mathrm{TiH}_{2}$ and Al Powder Mixture
}

Fei $\mathrm{Li}^{1,2, * \mathbb{C}}$, Xiao Zhang ${ }^{3, *}$, Yi Jiang ${ }^{1}$, Lixiang Yang ${ }^{1}$, Chengkang $\mathrm{Qi}^{1, *}$ and Baode Sun ${ }^{2}$

1 Shanghai Key Laboratory for High Temperature Materials and Precision Forming, Shanghai Jiao Tong University, Shanghai 200240, China; MarzPicture@sjtu.edu.cn (Y.J.); yanglixiang@sjtu.edu.cn (L.Y.)

2 State Key Laboratory of Metal Matrix Composites, Shanghai Jiao Tong University, Shanghai 200240, China; bdsun@sjtu.edu.cn

3 State Key Laboratory of Special Rare Metal Materials, Northwest Rare Metal Materials Research Institute Ningxia Co. Ltd., Shizuishan 735000, China

* Correspondence: lifei74@sjtu.edu.cn (F.L.); guofangkeji@163.com (X.Z.); chengkangq@sjtu.edu.cn (C.Q.); Tel.: +86-21-3420-2951 (F.L.); +86-952-2099-011 (X.Z.); +86-21-5474-2661 (C.Q.)

Received: 17 March 2019; Accepted: 11 April 2019; Published: 16 April 2019

\begin{abstract}
A porous TiAl alloy with $23.78 \%$ porosity was successfully fabricated via a low-toxicity, non-aqueous gel casting method by using a titanium hydride $\left(\mathrm{TiH}_{2}\right)$ and aluminum $(\mathrm{Al})$ powder mixture as the raw material. The effects of dispersant content and solid loading on the rheological properties of the $\mathrm{TiH}_{2} / \mathrm{Al}$ slurries were studied systematically. It was found that all the slurries exhibited a typical shear-thinning behavior, which is favorable for the gel casting process. Three-point bending tests of the dried $\mathrm{TiH}_{2} / \mathrm{Al}$ green bodies were carried out, and the results showed that the flexural strength was raised from 28.86 to $62.36 \mathrm{MPa}$ with increasing monomer (hydroxyethyl methacrylate, HEMA) content. In order to study the degreasing process and minimize the possible residual carbon and oxygen after sintering, TGA analysis was performed. The fracture morphology of the sintered TiAl alloy $\left(1400{ }^{\circ} \mathrm{C}\right.$ for $2 \mathrm{~h}$ ) was studied by scanning electron microscope (SEM). Based on the $X$-ray diffraction (XRD) identification, the main phases of the sintered part were $\gamma$-TiAl, $\alpha_{2}-\mathrm{Ti}_{3} \mathrm{Al}$, and a small amount of $\mathrm{Al}_{2} \mathrm{Ti}$ and $\mathrm{Al}_{3} \mathrm{Ti}$.
\end{abstract}

Keywords: TiAl alloy; gel casting; titanium hydride; sintering; porosity

\section{Introduction}

On the basis of their low density, high modulus, high temperature strength, good flame retardancy, excellent oxidation resistance, and creep resistance, TiAl alloys have been developed into one of the most attractive materials for lightweight and heat-resistant structural parts, such as those used in aviation, aerospace, aeronautical missiles, automotive engines, and so on [1-5]. In recent years, there has also been great interest in porous TiAl alloys as potential engineering materials for various industrial fields [6-9]. However, the traditional processing routes for preparing TiAl alloys, such as ingot metallurgy, hot forging, precision casting, powder metallurgy, and machining [10-14], either have long production cycles or waste quite a few materials, leading not only to high manufacturing costs, but also to difficulty in fully realizing the advantages in the preparation of parts with complex shapes. Therefore, it is of great importance to apply an appropriate technology to overcome the shortcomings mentioned above.

Gel casting, as a near net shaping technology, was firstly developed by Janney and Omatete in the early 1990s and has been widely applied in the ceramic industry [15-18]. In such a process, a high-solid-loading slurry consisting of raw powders, solvent, and organic binder is first required. 
After the slurry is casted into a mold, the organic binder creates a macromolecular network to hold the ceramic particles together. Homogeneous green bodies with the required mechanical properties are therefore obtained. In the past few decades, a considerable amount of research has been done on the development of the ceramic gel casting technique. Along with the constant maturity of gel casting technology, the applications have been expanded to the domain of metal materials [19-22].

It is well known that the performance of titanium-based objects can be easily deteriorated by impurities resulting from residual oxygen, nitrogen, and carbon during manufacturing [23]. Due to the high stability of these impurities, such as $\mathrm{TiO}_{2}$ and $\mathrm{TiN}$, it is impossible to eliminate them by using titanium or its elemental powder as a raw material. Fortunately, titanium hydride can be an ideal raw material to reduce the content of these impurities. In a previous work, the powder metallurgy of $\mathrm{TiH}_{2}$ and $\mathrm{TiH}_{2} / \mathrm{Al}$ was studied. Researchers, such as Kendra and Guo, also carried out impressive works on the gel casting of $\mathrm{TiH}_{2}$, and their results showed that oxygen and carbon contamination could be reduced [24-26].

In this study, a porous TiAl alloy was fabricated via non-aqueous gel casting followed by a vacuum sintering process by using $\mathrm{TiH}_{2} / \mathrm{Al}$ as raw powders. The main purpose of the present work is to further develop a simple approach for TiAl structural material production which could meet the requirements of reducing the cost and expanding application areas.

\section{Materials and Methods}

The low-toxicity gel casting system used was composed of $\mathrm{N}, \mathrm{N}$-dimethylformamide (DMF) as solvent, hydroxyethyl methacrylate (HEMA) as monomer, 1,6-hexanediol diacrylate (HDDA) as cross-linker, tert-butyl peroxybenzoate (TBPB) as initiator, and polyvinyl pyrrolidone (PVP) as dispersant. All the reagents were chemically pure and supplied by Shanghai National Pharmaceutical Reagents Group Co. Ltd., China. Commercially available $99.7 \%$ pure $\mathrm{TiH}_{2}$ powder (supplied by Shanghai Bike New Materials Co. Ltd., Shanghai, China) and $99.85 \%$ pure Al powder (supplied by Shanghai Bike New Materials Co. Ltd., Shanghai, China) were used as raw materials.

Premixed solutions containing $15 \mathrm{vol} \%$ to $40 \mathrm{vol} \%$ monomer relative to the volume of the solutions were prepared by dissolving HEMA, HDDA, and PVP in DMF at room temperature by means of ultrasonic dispersion. $\mathrm{A} \mathrm{TiH}_{2}$ and $\mathrm{Al}$ powder mixture with a molar ratio of 1:1 was added to the solutions and mixed by a stirrer for about $30 \mathrm{~min}$ to obtain $40 \mathrm{vol} \%$ to $48 \mathrm{vol} \% \mathrm{TiH}_{2} / \mathrm{Al}$ slurries. In all experiments, the ratio of HEMA to HDDA was fixed at 15:1. Later, a little dose of TBPB was dropped into the slurries and fully stirred. After that, the slurries were poured into individual silicone molds and held at $80^{\circ} \mathrm{C}$ in a vacuum drying chamber for $2 \mathrm{~h}$ to complete the gelation process. Subsequently, the wet green bodies were carefully removed from the molds and soaked in ethanol for $8 \mathrm{~h}$ in order to remove residual solvent. To avoid cracking during drying, the green bodies were dried in a vacuum chamber at 25,80 , and $120^{\circ} \mathrm{C}$ for $8 \mathrm{~h}$ in sequence. Finally, the $\mathrm{TiH}_{2} / \mathrm{Al}$ green bodies were sintered at $1400^{\circ} \mathrm{C}$ under vacuum conditions for $2 \mathrm{~h}$.

The particle size distributions of the $\mathrm{TiH}_{2}$ and $\mathrm{Al}$ powders were measured by a laser analyzer (S3500, Microtrac, USA). The micromorphology of the powders and the fracture surfaces of the green and sintered bodies were observed by a scanning electron microscope (Nova Nano SEM 230, FEI, USA). The rheological behavior of the $\mathrm{TiH}_{2} / \mathrm{Al}$ slurries was measured at room temperature by a rotary rheometer (Gemini 200HR, Bolin, UK) with the shearing rate ranging from 0 to $1000 \mathrm{~s}^{-1}$. The flexural strength of the green bodies was measured by a universal testing machine (Z020, Zwick/Roell, German) with a crosshead speed of $1 \mathrm{~mm} / \mathrm{min}$. Samples with a size of $40 \mathrm{~mm} \times 5 \mathrm{~mm} \times 5 \mathrm{~mm}$ for the test were held in a vacuum chamber at $120^{\circ} \mathrm{C}$ for $2 \mathrm{~h}$ to avoid the influence of moisture before testing. The degreasing process of the dried green body was studied by using a TG analyzer (TGA8000TM, PerkinElmer, USA), and the samples were heated at a rate of $10^{\circ} \mathrm{C} / \mathrm{min}$ from room temperature to $700{ }^{\circ} \mathrm{C}$ under a pure argon flow. An X-ray diffraction analyzer (D/max 2500, Rigaku, Japan) was used to identify the phases of the sintered samples. The porosity and pore size distribution of the sintered component were detected by a mercury intrusion method. 


\section{Results}

The SEM micrographs of the $\mathrm{TiH}_{2}$ and $\mathrm{Al}$ powders are shown in Figure $1 \mathrm{a}, \mathrm{b}$, respectively. It can be seen from Figure 1a that most $\mathrm{TiH}_{2}$ particles have an irregular polygonal shape and a rugged surface. $\mathrm{Al}$ particles are mostly hollow and spherical and much smaller than $\mathrm{TiH}_{2}$ particles. The particle size distribution analysis is presented in Figure 2, and the result shows that the $\mathrm{TiH}_{2}$ particles have a wide size distribution with a D50 of $21.7 \mu \mathrm{m}$, while the Al particles have a narrow size distribution with a D50 of $1.58 \mu \mathrm{m}$. The results of the size distributions are in keeping with the SEM micrographs in Figure 1.
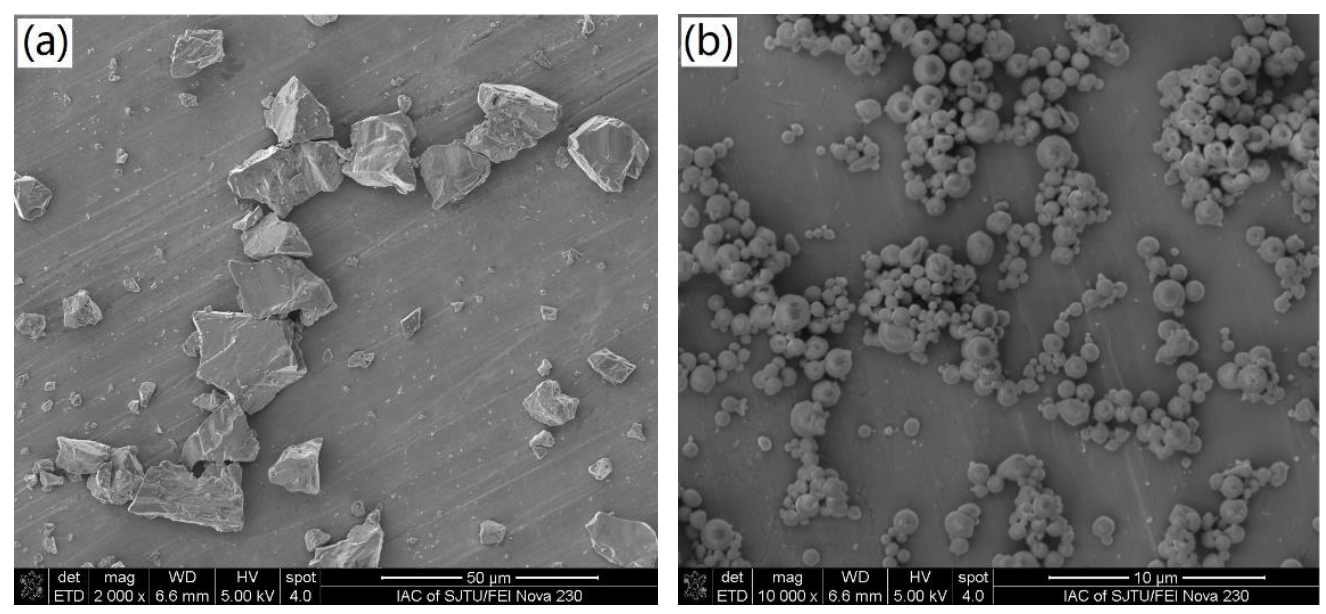

Figure 1. SEM micrographs of (a) $\mathrm{TiH}_{2}$ and (b) Al particles.

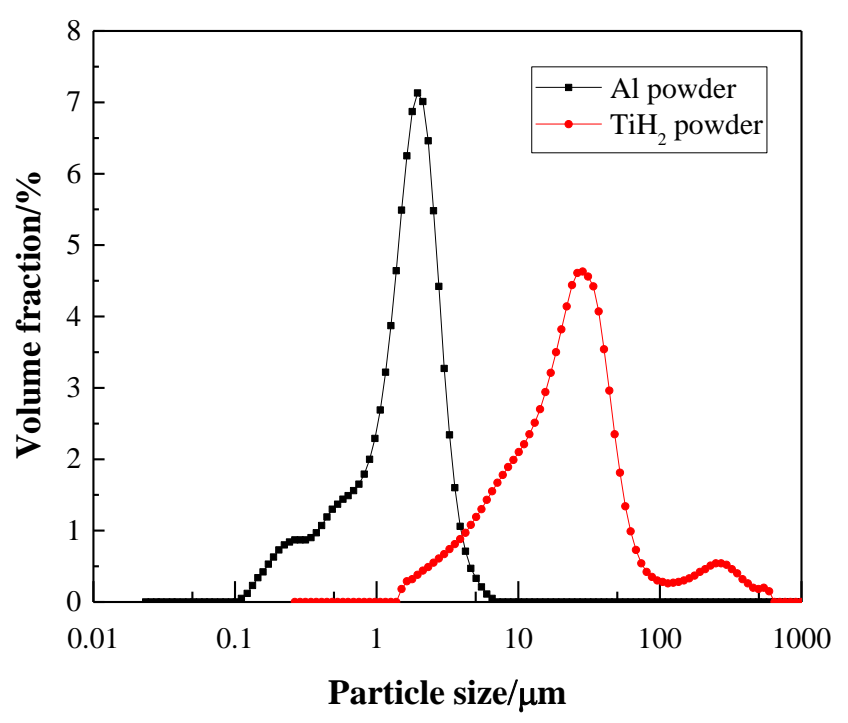

Figure 2. Size distribution curves of $\mathrm{TiH}_{2}$ and $\mathrm{Al}$ Powders.

For gel casting, it is quite essential to obtain stable slurries with good fluidity; hence, dispersants are added to stabilize solid particles and avoid aggregation or subsidence. There are mainly three mechanisms of dispersion, namely, steric hindrance, electrostatic repulsion, and their combination. In non-aqueous gel casting, steric hindrance dominates [27]. Therefore, polymer dispersants which have a strong steric effect are preferred. In this study, PVP was chosen as the dispersant, and the rheological properties of $\mathrm{TiH}_{2} / \mathrm{Al}$ slurries with a solid content of $46 \mathrm{vol} \%$ were measured by a rotary rheometer. During the preparation of $\mathrm{TiH}_{2} / \mathrm{Al}$ slurries, it was found that when the ratio of PVP to powder mass was less than $1 \mathrm{wt} \%, \mathrm{TiH}_{2}$ particles were easily sedimented due to their big size and 
density of $3.8 \mathrm{~g} / \mathrm{cm}^{3}$, which would result in a non-uniform distribution of powders. Hence, a sufficient dose of PVP was needed. Three PVP addition ratios relative to the $\mathrm{TiH}_{2} / \mathrm{Al}$ powder mixture were chosen: 1, 2, and $3 \mathrm{wt} \%$. The effects of the dispersant dosage on the rheological behavior of the $\mathrm{TiH}_{2} / \mathrm{Al}$ slurries are shown in Figure 3. It can be seen that all the $\mathrm{TiH}_{2} / \mathrm{Al}$ slurries exhibited a shear-thinning behavior over the measured shear rate range, which indicates that the $\mathrm{TiH}_{2}$ and $\mathrm{Al}$ particles were in the flocculation state in the static slurries. When shear force was applied, the flocculation structure was dismantled and the apparent viscosities decreased. Once the flocculation structure in the slurries was completely dismantled, the viscosities did not decrease anymore. In addition, both the apparent viscosity and the shear stress of the slurries increased while the PVP content rose from 1 to $3 \mathrm{wt} \%$. At the shear rate of $100 \mathrm{~s}^{-1}$, the slurry prepared from the precursor solution containing $1 \mathrm{wt} \% \mathrm{PVP}$ relative to the $\mathrm{TiH}_{2} / \mathrm{Al}$ powders exhibited a shear viscosity of $169.3 \mathrm{mPa} \cdot \mathrm{s}$, while the slurries with $2 \mathrm{wt} \%$ and $3 \mathrm{wt} \%$ PVP displayed viscosities as high as $382.6 \mathrm{mPa} \cdot \mathrm{s}$ and $919.2 \mathrm{mPa} \cdot \mathrm{s}$, respectively. For the sake of adequate mold filling, $\mathrm{TiH}_{2} / \mathrm{Al}$ slurries with low viscosity were necessary, and $1 \mathrm{wt} \%$ was chosen as the optimum amount of PVP addition to the slurry.

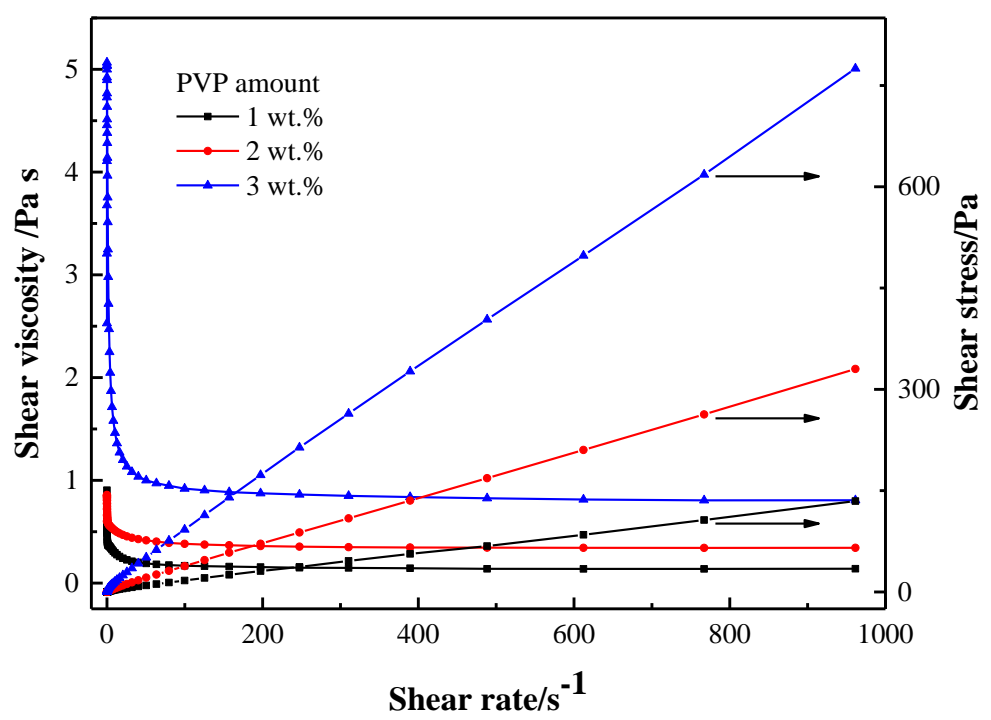

Figure 3. Effects of the PVP dispersant amount on the rheological properties of the $\mathrm{TiH}_{2} / \mathrm{Al}$ slurries.

For the gel casting process, the solid loading of the slurry has great effects on the fluidity of the slurry and the density of the green and sintered parts. Low viscosity of the slurry is conducive to uniform filling of the mold, while high solid loading has the benefit of reducing the volume shrinkage and increasing the sintering density of the green body during drying and sintering, which is particularly important for the deformation control of products with a complex structure. However, low viscosity and high solid loading of the slurry often contradict each other. Therefore, a balance between the two must be considered when preparing a gel casting slurry.

Figure 4 shows the respective rheological curves of the $\mathrm{TiH}_{2} / \mathrm{Al}$ slurries with solid loadings of 40 , $42,44,46$, and $48 \mathrm{vol} \%$. As expected, the apparent viscosity and shear stress of the slurries displayed a remarkable increasing tendency with the rise of the solid loading content. The slurry with a solid loading of $46 \mathrm{vol} \%$ possessed a shear viscosity of $393.5 \mathrm{mPa} \cdot \mathrm{s}$ at the shear rate of $100 \mathrm{~s}^{-1}$ and an intimal viscosity less than $1000 \mathrm{mPa} \cdot \mathrm{s}$, which is enough to meet the requirements of gel casting. The shear stress versus shear rate in Figure 5 could be further analyzed using the Herschel-Buckley model [28]:

$$
\tau=\tau_{0}+\mathrm{k} \gamma \mathrm{n}
$$


where $\tau$ is the shear stress, $\tau_{0}$ the yield stress, $\mathrm{k}$ is a consistency coefficient, $\gamma$ is the shear rate, and $\mathrm{n}$ is the flow behavior index. According to the rheological properties of the $\mathrm{TiH}_{2} / \mathrm{Al}$ slurries shown in Figures 3 and 4, it is evident that the slurries belong to typical pseudoplastic fluids [28].

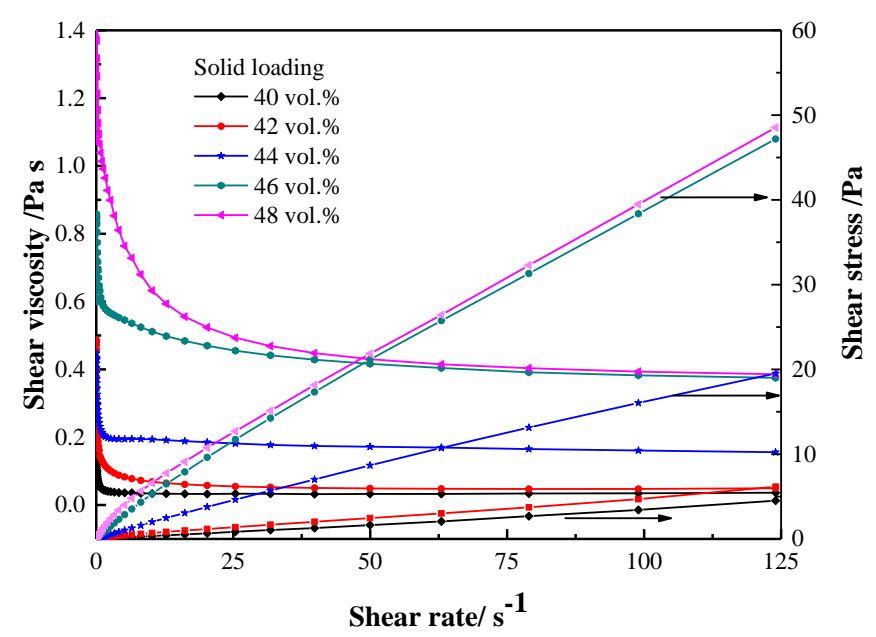

Figure 4. Effects of the solid loading on the rheological properties of the $\mathrm{TiH}_{2} / \mathrm{Al}$ slurries.

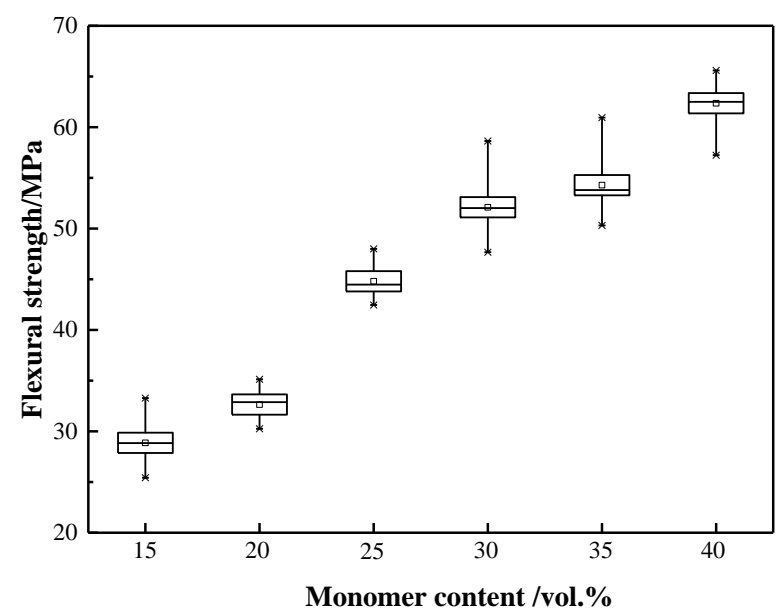

Figure 5. Effect of monomer content on flexural strength of dried bodies derived from the 46 vol \% $\mathrm{TiH}_{2} / \mathrm{Al}$ slurry.

In order to avoid cracking during demolding, the strength of the gel-casted body must be considered while fabricating complex-shaped parts. Figure 5 shows the effect of monomer contents on the flexural strength of the green bodies. It can be seen from Figure 5 that with the increase of the monomer contents from 15 to $40 \mathrm{vol} \%$, the flexural strengths of the green bodies increased from 28.86 to $62.36 \mathrm{MPa}$. This might be due to the increasing monomer content bringing more polymer networks in per unit volume, leading to increased strength.

Figure 6 shows the fracture micrograph of $\mathrm{TiH}_{2} / \mathrm{Al}$ green bodies with different monomer contents when the solid loading is $46 \mathrm{vol} \%$. It can be seen from Figure 6 that when the gelled polymer contents in the green bodies are relatively low (Figure 6a-d), the spherical state of the Al particles can still be observed, while the $\mathrm{TiH}_{2}$ particles are also encapsulated by the polymer and partly covered by $\mathrm{Al}$ particles. Meanwhile, there are some pores in those bodies. Some of the pores could be attributed to the pull-out of the $\mathrm{TiH}_{2}$ particles when the green body was broken off. It was also found from the experiment that when the monomer content is too high (for example, over $35 \mathrm{vol} \%$ ), the slurry solidifies quickly and is not easy to control. Meanwhile, in the processes of degreasing and sintering, more polymer in the green bodies might lead to more residues, which would have adverse effects on 
the properties of the sintered bodies. Therefore, the suitable monomer dosage determined in this study was $30 \mathrm{vol} \%$.
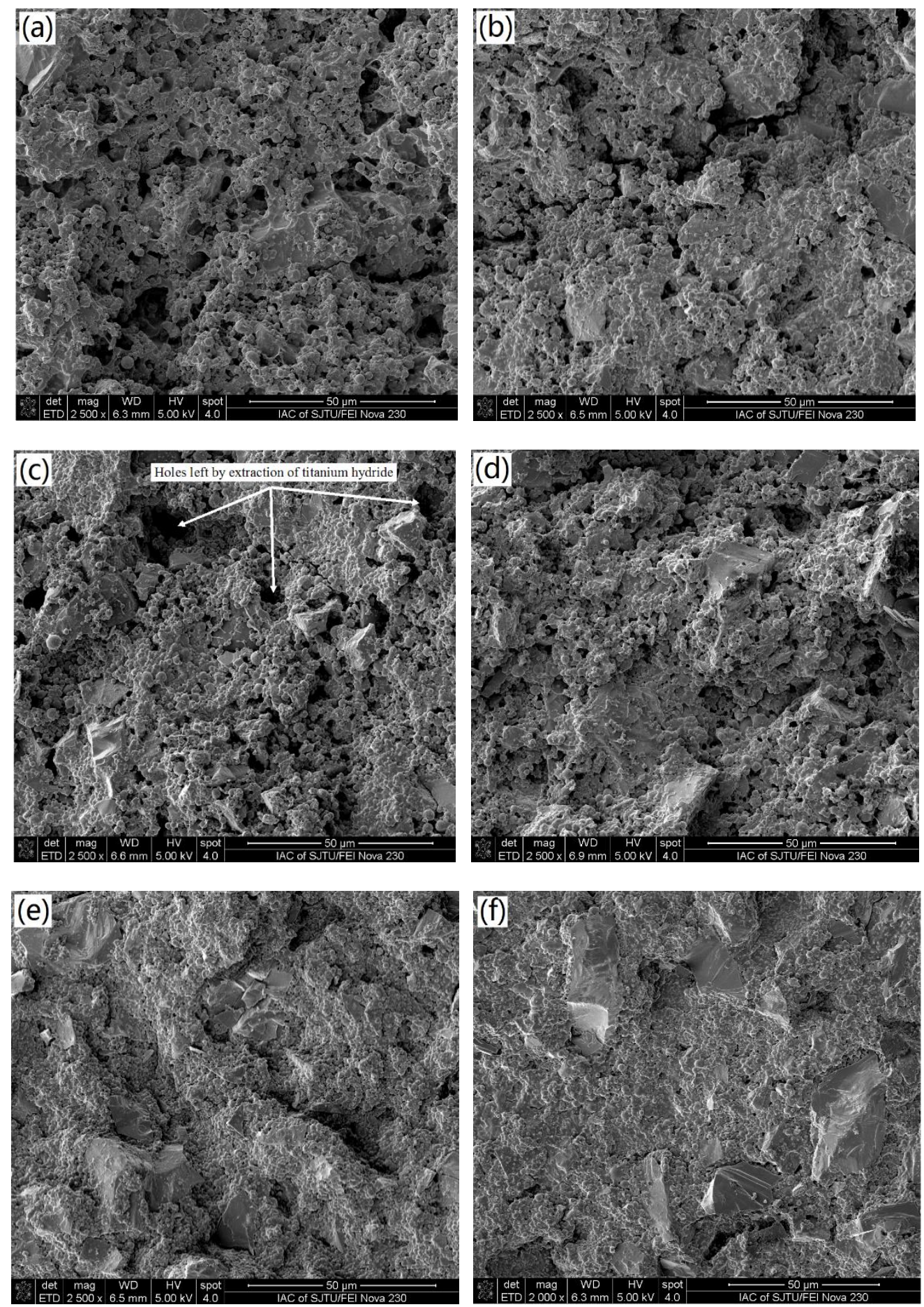

Figure 6. Cross-sectional micrographs of $\mathrm{TiH}_{2} / \mathrm{Al}$ green bodies gel casted from slurries with different monomer contents. (a) $15 \mathrm{vol} \%$, (b) $20 \mathrm{vol} \%$, (c) $25 \mathrm{vol} \%$, (d) $30 \mathrm{vol} \%$, (e) $35 \mathrm{vol} \%$, and (f) $40 \mathrm{vol} \%$.

Figure 7 shows the thermogravimetric curve of the green body with a monomer content of $30 \mathrm{vol} \%$ and a solid loading of $46 \mathrm{vol} \%$. As can be seen from Figure 7, the thermogravimetric curve of the $\mathrm{TiH}_{2} / \mathrm{Al}$ green body can be divided into four stages (s1-s4). The first stage is from room temperature to $300{ }^{\circ} \mathrm{C}$. In this temperature range, the weight loss of the sample is about $2 \%$, which corresponds to the 
volatilization of the solvent and the initial decomposition of the gelled polymer. The second stage is from 300 to $500{ }^{\circ} \mathrm{C}$. In this temperature range, the weight loss of the sample is about $9 \%$, corresponding to the massive decomposition of the polymer network, and the DTG curve also indicates that the decomposition rate reaches its maximum value near $418^{\circ} \mathrm{C}$. The third stage is from 500 to $620^{\circ} \mathrm{C}$. The weight of the sample remains unchanged, indicating that the burning of the polymer is basically completed, but $\mathrm{TiH}_{2}$ does not dehydrogenate obviously. In the fourth stage, from 620 to $700{ }^{\circ} \mathrm{C}$, a small amount of thermal weight loss occurs, corresponding to the dehydrogenation process of $\mathrm{TiH}_{2}$, i.e., $\mathrm{TiH}_{2} \rightarrow \mathrm{TiHx} \rightarrow \alpha$-Ti $(0.7<\mathrm{x}<1.1)$ [29]. According to the above thermal analysis results, $\mathrm{TiH}_{2} / \mathrm{Al}$ green bodies should be kept at a temperature range of 300 to $500{ }^{\circ} \mathrm{C}$ for a long time under a low heating rate during sintering to ensure that all the gelled polymer is decomposed completely.

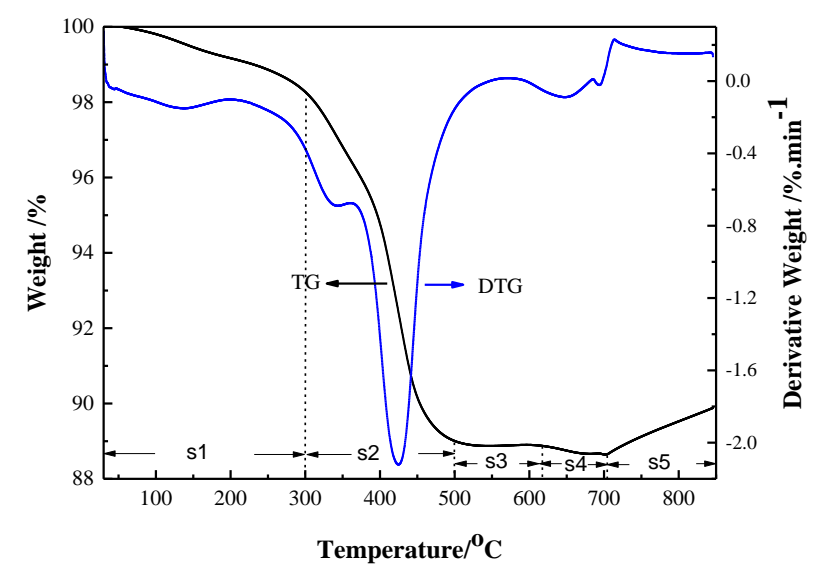

Figure 7. Thermogravimetric curve of the $\mathrm{TiH}_{2} / \mathrm{Al}$ green body by TGA.

Figure 8 shows the microstructure of the TiAl alloy sintered at $1400{ }^{\circ} \mathrm{C}$ under vacuum conditions for $2 \mathrm{~h}$. It can be seen from Figure 8 that some open pores with sizes of several microns exist in the sintered part with a typical fracture cleavage surface. The peak intensities from an XRD pattern (Figure 9) of TiAl alloys sintered at $1400{ }^{\circ} \mathrm{C}$ mainly identified the phases as $\gamma$-TiAl and $\alpha_{2}-\mathrm{Ti}_{3} \mathrm{Al}$ with a small amount of $\mathrm{TiAl}_{2}$ and $\mathrm{TiAl}_{3}$. It is evident that residuals from organic additives had been eliminated since no carbide phase was detected by XRD. Figure 10 is the pore size distribution curve for the TiAl alloy sample sintered at $1400^{\circ} \mathrm{C}$. It can be seen from Figure 10 that the sample has a narrow pore size distribution of 2 to 8 microns and its median pore diameter is 3.57 microns, which matches the SEM observation shown in Figure 8. The porosity and apparent density of the as-sintered TiAl alloy are $23.78 \%$ and $4.01 \mathrm{~g} / \mathrm{cm}^{3}$, respectively.
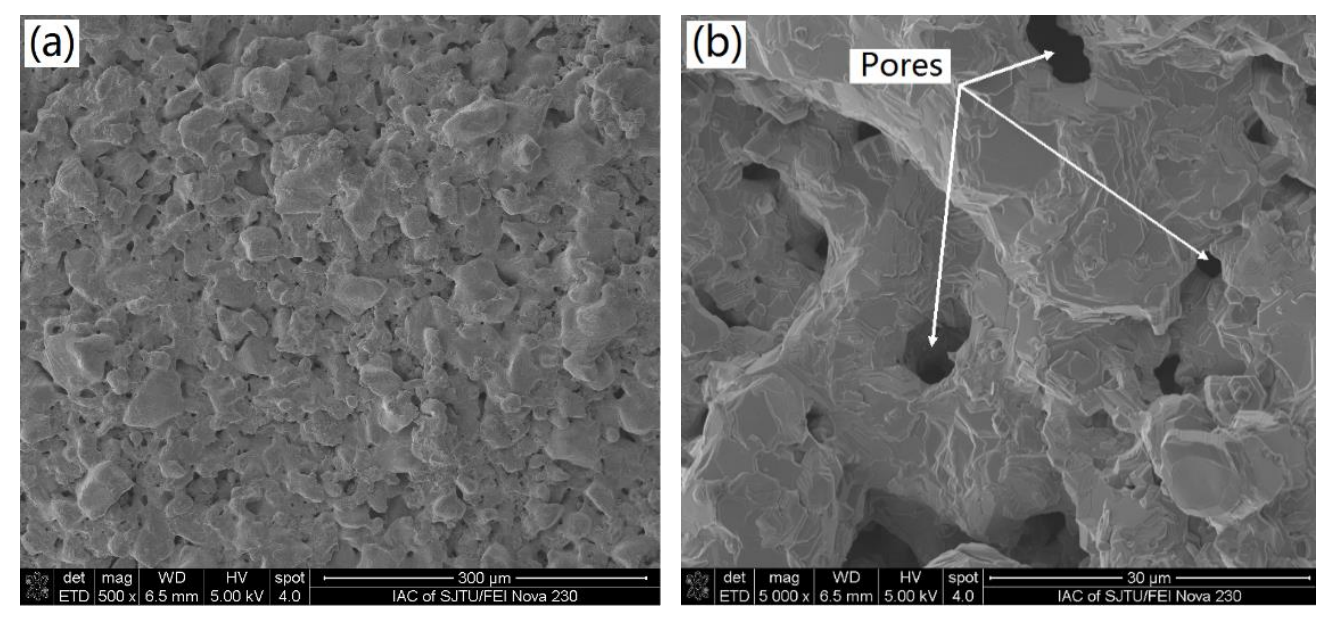

Figure 8. SEM micrographs of sintered TiAl alloys. (a) $500 \times$ and (b) $5000 \times$. 


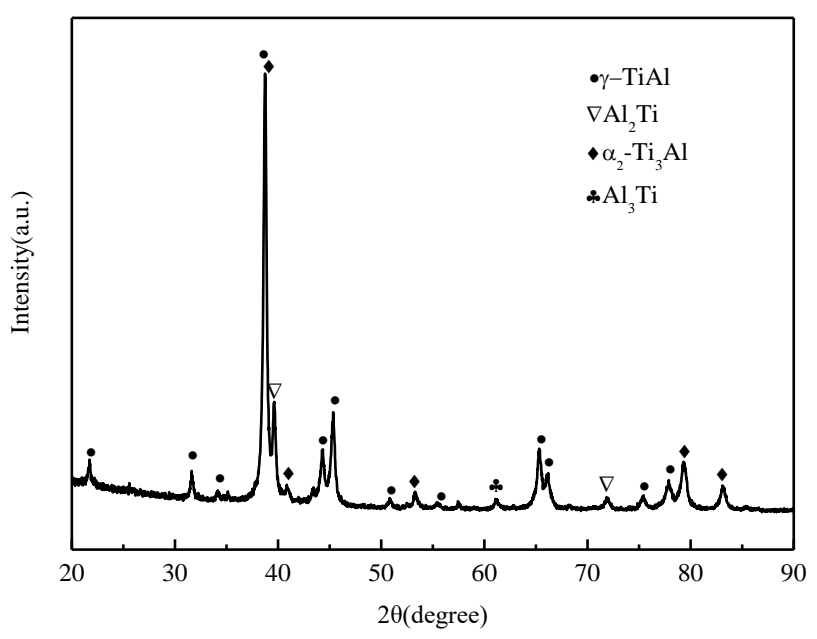

Figure 9. XRD pattern of TiAl alloy after the sintering process.

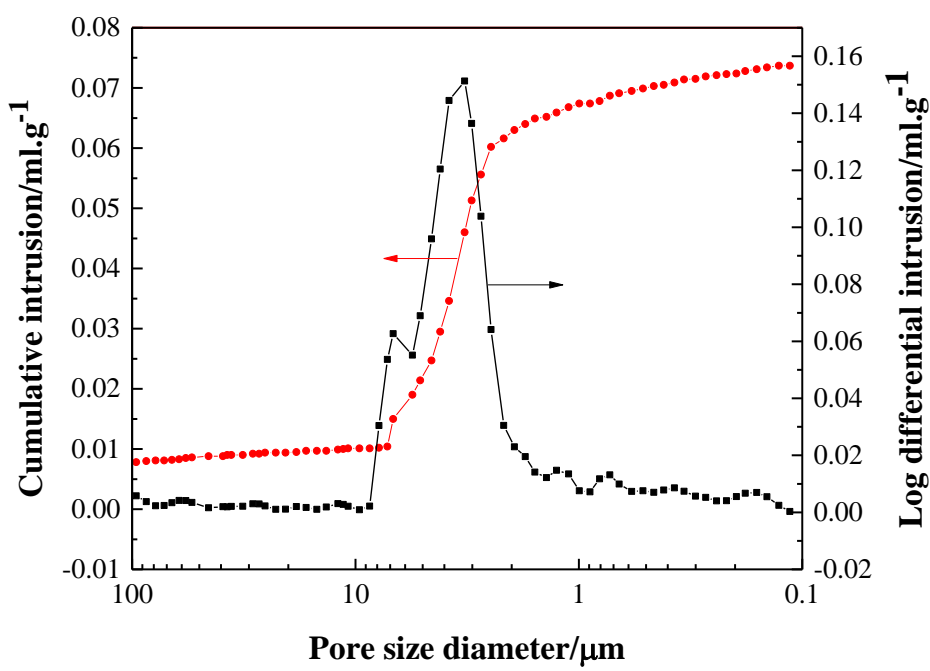

Figure 10. Pore size distribution of the TiAl alloy sintered at $1400{ }^{\circ} \mathrm{C}$ in vacuum for $2 \mathrm{~h}$.

\section{Conclusions}

This work described a non-aqueous gel casting process with potential for fabricating porous and complicated TiAl components. Based on the characterization of the raw materials, the rheological properties of the slurries for gel casting, the mechanical and thermal properties of green bodies, and the microstructure and phase composition of the sintered part presented above, the following conclusions can be drawn:

1. A non-aqueous $\mathrm{TiH}_{2} / \mathrm{Al}$ slurry system for gel casting was developed, which exhibited shear-thinning behavior and was favorable for the gel casting process of $\mathrm{TiH}_{2} / \mathrm{Al}$ green bodies with a complex shape. The optimum amount of PVP addition to the slurry was $1 \mathrm{wt} \%$ relative to the $\mathrm{TiH}_{2} / \mathrm{Al}$ powder mixture.

2. The monomer contents have a great effect on the mechanical properties of the $\mathrm{TiH}_{2} / \mathrm{Al}$ green bodies. The flexural strength of the green bodies increased from 28.86 to $62.36 \mathrm{MPa}$ as the monomer contents in the premix solution increased from 15 to $40 \mathrm{vol} \%$ relative to the premix solution. The suitable monomer dosage determined was $30 \mathrm{vol} \%$ relative to the volume of the solutions.

3. The sintered TiAl alloy exhibited a typical fracture cleavage surface; meanwhile, its pore size distribution was $2 \mu \mathrm{m}$ to $8 \mu \mathrm{m}$ and its porosity was $23.78 \%$, which indicates that the gel casting route is a suitable way to prepare porous TiAl alloy components. The result of the XRD analysis 
shows that $\gamma$-TiAl and $\alpha_{2}-\mathrm{Ti}_{3} \mathrm{Al}$ were the main phases and no contaminated carbide phase was formed.

Author Contributions: Conceptualization: F.L.; methodology: F.L. and X.Z.; investigation: L.Y., Y.J. and X.Z.; data curation: C.Q.; writing—original draft preparation: F.L.; writing—review and editing: C.Q.; supervision: B.S.

Funding: This research was funded by the National Science and Technology Major Project "Aero engine and Gas Turbine," grant number 2017-VII-0008-0102, the Shanghai Municipal Science and Technology Innovation Action Plan under Project, grant number CXY-2016-004 and the "13th Five-Year" equipment pre research and sharing technology project, grant numbers 41423040203 and 41423040206.

Acknowledgments: We thank Ying Zhang (Analysis and Testing Center of Shanghai Jiao Tong University) for her help with running SEM pictures. We also gratefully acknowledge helpful discussions with Yanjie Zhao and Junhua Lai.

Conflicts of Interest: The authors declare no conflict of interest.

\section{References}

1. Yamaguchi, M.; Inui, H.; ITO, K. High-temperature structural intermetallics. Acta Mater. 2000, 48, $307-322$. [CrossRef]

2. Wu, X. Review of alloy and process development of TiAl alloys. Intermetallics 2006, 14, 115-122. [CrossRef]

3. Imayev, R.M.; Imayev, V.M.; Oehring, M.; Appel, F. Alloy design concepts for refined gamma titanium aluminide based alloys. Intermetallics 2007, 15, 451-460. [CrossRef]

4. Peters, M.; Kumpfert, J.; Ward, C.H.; Leyens, C. Titanium alloys for aerospace applications. Adv. Eng. Mater. 2003, 5, 419-427. [CrossRef]

5. Coro, A.; Abasolo, M.; Aguirrebeitia, J.; López de Lacalle, L.N. Inspection scheduling based on reliability updating of gas turbine welded structures. Adv. Mech. Eng. 2019, 11, 1-20. [CrossRef]

6. Rak, Z.S.; Walter, J. Porous titanium foil by tape casting technique. J. Mater. Process. Technol. 2006, 175, 358-363. [CrossRef]

7. He, Y.H.; Jiang, Y.; Xu, Y.N.P.; Zou, J.; Huang, B.Y.; Liu, C.T.; Peter, K.L. Fabrication of Ti-Al micro/nanometer-sized porous alloys through the Kirkendall effects. Adv. Mater. 2007, 19, 2102-2106. [CrossRef]

8. Qin, P.; Yang, B.; Liu, L.B.; Song, C.J.; Friedrich, B. Porous TiAl alloys fabricated by sintering of $\mathrm{TiH}_{2}$ and $\mathrm{Al}$ powder mixtures. J. Alloys Compd. 2016, 656, 530-538.

9. Hao, G.L.; Xu, Q.P.; Wang, H.; Li, X.Y. Effect of pore structure on mechanical properties of porous TiAl. Mater. Sci. Technol. 2016, 32, 1592-1596. [CrossRef]

10. Lascano, S.; Arevalo, C.; Montealegre-Melendez, I.; Munoz, S.; Rodriguez-Ortiz, J.A.; Trueba, P.; Torres, Y. Porous titanium for biomedical applications: Evaluation of the conventional powder metallurgy frontier and space-holder technique. Appl. Sci. 2019, 9, 982. [CrossRef]

11. Jovanovic, M.T.; Dimcic, B.; Bobic, I.; Zec, S.; Maksimovic, V. Microstructure and mechanical properties of precision cast TiAl turbocharger wheel. J. Mater. Process. Technol. 2005, 167, 14-21. [CrossRef]

12. Tetsui, T.; Shindo, K.; Kaji, S.; Kobayashi, S.; Takeyama, M. Fabrication of TiAl Components by means of hot forging and machining. Intermetallics 2005, 13, 971-978. [CrossRef]

13. Clemens, H.; Kestler, H. Processing and applications of intermetallic $\gamma$-TiAl-based alloys. Adv. Eng. Mater. 2000, 9, 551-570. [CrossRef]

14. Kothari, K.; Radhakrishnan, R.; Wereley, N.M. Advances in gamma titanium aluminides and their manufacturing techniques. Prog. Aerosp. Sci. 2012, 55, 1-16. [CrossRef]

15. Young, A.C.; Omatete, O.O.; Janney, M.A.; Menchhofer, P.A. Gelcasting of alumina. J. Am. Ceram. Soc. 1991, 74, 612-618. [CrossRef]

16. Omatete, O.O.; Janney, M.A.; Nunn, S.D. Gelcasting: From laboratory development towards industrial production. J. Eur. Ceram. Soc. 1997, 17, 407-413. [CrossRef]

17. Lewis, J.A. Colloidal processing of ceramics. J. Am. Ceram. Soc. 2000, 83, 2341-2359. [CrossRef]

18. Franks, G.V.; Tallon, C.; Studart, A.R.; Sesso, M.L.; Leo, S. Colloidal processing: Enabling complex shaped ceramics with unique multiscale structures. J. Am. Ceram. Soc. 2017, 100, 1-33. [CrossRef]

19. Hernandez, N.; Sanchez-Herencia, A.J.; Moreno, R. Forming of nickel compacts by a colloidal filtration route. Acta Mater. 2005, 53, 919-925. [CrossRef] 
20. Lu, Z.L.; Cao, J.W.; Bai, S.Z.; Wang, M.Y.; Li, D.C. Microstructure and mechanical properties of TiAl-based composites prepared by stereolithography and gelcasting technologies. J. Alloys Compd. 2015, 633, 280-287. [CrossRef]

21. Biasetto, L.; Moraes, E.G.; Colombo, P.; Bonollo, F. Ovalbumin as foaming agent for $\mathrm{Ti}_{6} \mathrm{Al}_{4} \mathrm{~V}$ foams produced by gelcasting. J. Alloys Compd. 2016, 687, 839-844. [CrossRef]

22. Lux, J.; Moraes, E.G.; Maire, E.; Adrien, J.; Biasetto, L. Gas permeability of $\mathrm{Ti}_{6} \mathrm{Al}_{4} \mathrm{~V}$ foams prepared via gelcasting, experiments and modelling. Comp. Mater. Sci. 2018, 152, 363-373. [CrossRef]

23. Azevedo, C.R.F.; Rodrigues, D.; Neto, F.B. Ti-Al-V powder metallurgy (PM) via the hydrogenation-dehydrogenation (HDH) process. J. Alloys Compd. 2003, 353, 217-227. [CrossRef]

24. Erk, K.A.; Dunand, D.C.; Shull, K.R. Titanium with controllable pore fractions by thermoreversible gelcasting of $\mathrm{TiH}_{2}$. Acta Meter. 2008, 56, 5147-5157. [CrossRef]

25. Li, Y.; Guo, Z.M.; Hao, J.J.; Ren, S.B. Porosity and mechanical properties of porous titanium fabricated by gelcasting. Rare Met. 2008, 27, 282-286. [CrossRef]

26. Ye, Q.; Guo, Z.M.; Bai, J.L.; Lu, B.X.; Lin, J.P.; Hao, J.J.; Luo, L.; Shao, H.P. Gelcasting of titanium hybride to fabricate low-cost titanium. Rare Met. 2015, 34, 351-356. [CrossRef]

27. Studart, A.R.; Amstad, E.; Gauckler, L.J. Colloidal stabilization of nanoparticles in concentrated suspensions. Langmuir 2008, 23, 1081-1090. [CrossRef]

28. Lin, T.R.; Lin, J.F. The elastohydrodynamic lubrication of line contacts with pseudoplastic fluids. Wear 1990, 140, 235-249.

29. Jimenez, C.; Garcia-Moreno, F.; Pfretzschner, B.; Klaus, M.; Wollgarten, M.; Zizak, I.; Schumacher, G.; Tovar, M.; Banhart, J. Decomposition of $\mathrm{TiH}_{2}$ studied in situ by synchrotron X-ray and neutron diffraction. Acta Mater. 2011, 59, 6318-6330. [CrossRef]

(C) 2019 by the authors. Licensee MDPI, Basel, Switzerland. This article is an open access article distributed under the terms and conditions of the Creative Commons Attribution (CC BY) license (http://creativecommons.org/licenses/by/4.0/). 